\title{
Erratum to: Christianity: A Culture of Transnational Mobility
}

Catherine Gomes, Jonathan Tan

(C) The Editor(s) (if applicable) and The Author(s) 2017

C. Gomes, Transient Mobility and Middle Class Identity, DOI 10.1007/978-981-10-1639-4

DOI 10.1007/978-981-10-1639-4_10

The heading of chapter seven has been changed from

Christianity: A Culture of Transnational Mobility with Jonathan Tan TO

Christianity: A Culture of Transnational Mobility

The updated original online version for this chapter can be found at http://dx.doi.org/DOI 10.1007/978-981-10-1639-4_7

(C) The Editor(s) (if applicable) and The Author(s) 2017 
